\title{
A indústria farmacêutica no Brasil e na Índia: um estudo comparativo
}

Mariane Santos Françoso ${ }^{1}$

Eduardo Strachman ${ }^{2}$

\begin{abstract}
Resumo: O artigo mostra como se deu o desenvolvimento da indústria farmacêutica no Brasil e na Índia, e por que a indústria desses dois países, que até a década de 1970 eram muito semelhantes, hoje apresentam significativas diferenças, principalmente em relação a tecnologia. A análise histórica das trajetórias da indústria nos dois países evidenciou que a indústria indiana apresenta maior conteúdo tecnológico, devido, entre outros, a eficiência de políticas públicas implantadas desde a década de 1970, que tinham como objetivo aumentar não apenas a produção, mas também o desenvolvimento tecnológico.
\end{abstract}

Palavras-chave: Indústria Farmacêutica; Política Industrial; Estrutura de Mercado; Brasil; Índia.

JEL: L22, L25, L52,L65

\section{The pharmaceutical industry in Brazil and India: a comparative study}

\begin{abstract}
The article shows how the development of the pharmaceutical industry in Brazil and India occurred, and why the industry in these two countries, which until the 1970 s were much alike, today show significant differences. The historical analysis of the trajectories of the industries in both countries showed that the Indian industry has a higher technological content, due to, among others, the efficiency of public policies implemented since the 1970s, which were aimed at improving not only production, but also the technological development.
\end{abstract}

Keywords: Pharmaceutical Industry; Industrial Policy; Market Structure; Brazil; India.

JEL: L22, L25, L52,L65

1 Mestranda no Departamento de Política Científica e Tecnológica, UNICAMP. E-mail: mariane_n86@yahoo.com.br

2 Prof. Adjunto no Departamento de Economia da UNESP Araraquara. Doutorado no Instituto de Economia da UNICAMP. E-mail: edstrach@fclar.unesp.br 


\section{Introdução}

Países emergentes têm assumido um papel importante no cenário mundial da indústria farmacêutica, tradicionalmente dominada pelos países da tríade, responsáveis por $87 \%$ das vendas mundiais. Isso se deve ao investimento recente feito pelas empresas nacionais destes países em desenvolvimento, as quais têm adquirido capacitações no segmento de genéricos.

A partir de 1970, o governo indiano deu início à implantação de uma série de políticas públicas, que favoreceram a criação de empresas nacionais, através da redução às barreiras a entrada. Além disso, essas políticas também favoreceram o acúmulo de capacitações, através da prática da engenharia reversa e da colaboração de institutos de pesquisa. Enquanto isso, o Brasil apresentou poucas políticas direcionadas ao desenvolvimento do setor, e, mesmo as implantadas, estavam mais voltadas ao aumento da produção e não ao acúmulo de capacitações.

Baseado nessas diferenças, quanto à capacitação da indústria farmacêutica nos dois países, este artigo tem como objetivo mostrar a trajetória de desenvolvimento do setor farmacêutico na Índia e no Brasil, destacando as políticas implantadas e o ambiente favorável à prática de $\mathrm{P} \& \mathrm{D}$ que foi criado, naquele país. O trabalho está dividido em quatro seções, além desta introdução e da conclusão. Na próxima, é realizada uma revisão bibliográfica teórica, posteriormente, é elaborado um panorama geral sobre a indústria farmacêutica e sua dinâmica competitiva. Em seguida, investigam-se as políticas implantadas, tanto no Brasil como na Índia, e as especificidades do desenvolvimento do setor, em cada um destes países. Por fim, é feita uma análise quanto à capacitação de empresas de capital nacional selecionadas, dos dois países.

\section{Referencial teórico}

Paul David (2000) mostra a importância da história, principalmente ao tratarmos de processos evolucionários, path dependent. Quando tratamos desses processos, devemos considerar, então, o contexto dinâmico em que estes estão inseridos, com frequentes mudanças tecnológicas e organizacionais, incrementais e, com muito menor periodicidade, radicais. O conceito de path dependence está relacionado ao fato de que as decisões tomadas hoje têm relação com as decisões tomadas anteriormente, pois estas últimas foram responsáveis pela criação de um contexto e um conjunto de recursos, que influi nas decisões tomadas pelas empresas hoje. 
O ambiente em que as firmas estão inseridas não é estático, muitas vezes ocorrendo mudanças que requerem que as firmas se adaptem. Teece e Pisano (1994) afirmam que as empresas que se saem bem nessas situações são aquelas que apresentam maior rapidez e flexibilidade, na realização de inovações e na administração eficiente das capacitações, entendidas, evolucionariamente, como a capacidade de as firmas adaptarem, integrarem e reconfigurarem adequadamente desenhos organizacionais, recursos e competências funcionais internas e externas, em meio a ambientes mutáveis. A fim de poderem se adaptar a novos ambientes, as firmas precisam ter capacitações dinâmicas, definidas como um subconjunto das capacitações, que permitem às firmas criar novos produtos, processos e desenhos organizacionais e responder às mudanças no mercado. Para Bell e Pavitt (1982), as capacitações podem ser também tecnológicas ou produtivas, sendo que uma não exclui ou inclui necessariamente a outra.

Capacitações tecnológicas estão, assim, relacionadas ao conjunto de habilidades, conhecimentos e instituições que compõem o potencial para gerar mudanças tecnológicas, enquanto a capacidade produtiva é o conjunto de bens de capital, conhecimentos e habilidades necessárias para produzir bens e serviços, a partir de certa tecnologia. Algumas empresas e/ou países têm capacidade produtiva, mas não capacidade tecnológica, e vice-versa. A capacidade produtiva está ligada à possibilidade de operar uma variação na produção de bens e serviços, em quantidade, eficiência ou custos, empregando ou não novas tecnologias na sua produção, enquanto a capacitação tecnológica relaciona-se à geração de mudanças tecnológicas e/ou organizacionais.

A capacidade de gerar mudanças técnicas depende intensamente de P\&D e do conhecimento já acumulado, pois as inovações que serão desenvolvidas estão diretamente relacionadas às capacitações acumuladas. Essas capacitações são geradas a partir de experiências, inovações anteriores e P\&D acumulado e em andamento. Assim, as rotinas adotadas anteriormente serão cruciais para o desenvolvimento de novas tecnologias, já que esse é um processo path dependent, ainda que possa haver rupturas e inovações radicais nestas rotinas, de tempos em tempos.

Esse fator cumulativo pode ser usado para explicar por que a capacitação tecnológica está concentrada e/ou tende a se concentrar nos países desenvolvidos. Pensando na indústria farmacêutica, as atividades de P\&D, historicamente, estão concentradas nos países de origem das empresas, geralmente EUA e países europeus, pois o acúmulo de capacitações nesses países é maior do que nos países em desenvolvimento, fazendo com que a maioria destes últimos esteja muito distante da fronteira tecnológica e necessite de incentivos e esforços para efetuar um emparelhamento (catch up) com estes países e empresas mais antigos.

Nas economias de industrialização recente (EIR), como Brasil e Índia, é necessário que existam políticas governamentais que incentivem e favore- 
çam o desenvolvimento das empresas locais, possibilitando a diminuição da dependência interna de determinados setores, principalmente os de alta tecnologia, que requerem grandes investimentos em atividades complexas e que têm significativas barreiras à entrada.

Nesse sentido, as políticas industriais podem ser cruciais, pois os custos relativos de aquisição inicial das capacidades necessárias são maiores do que os de "simples" manutenção de conhecimentos a pouca ou razoável distância dos líderes, a ponto que a aquisição destes ativos poder se mostrar difícil ou mesmo impossível sem auxílio estatal. Há uma série de recursos e desenvolvimentos que têm que ser criados para mudar a trajetória natural de um país. Em suma, o Estado pode ser responsável pela elaboração de uma estratégia para o surgimento de um conjunto de atividades, as quais podem até mesmo ser, em sua maior parte, ações típicas de empresas privadas, porém podendo também compreender atividades públicas, como educação, treinamento, infraestrutura etc. Uma estratégia estatal deve, então, interligar-se àquelas específicas das empresas privadas, procurando gerar sinergias, a fim de que as várias empresas acumulem recursos, tentando acercar-se progressivamente das posições de liderança (Strachman, 2009).

\section{A indústria farmacêutica no mundo}

A indústria farmacêutica é um setor no qual os investimentos em P\&D são intensivos, girando em torno dos $15 \%$ do faturamento, entre as líderes do setor. Uma importante característica dessa indústria é a concentração, sendo que os países da tríade (América do Norte, Europa Ocidental e Japão) respondem por $87 \%$ das vendas mundiais, e as dez maiores empresas do setor - duas americanas e oito europeias, de acordo com a revista Exame - têm um market share superior a 40\%. Alguns fatores são cruciais para esta concentração existente no setor: custo da P\&D, economias de escala, papel da demanda, condições de oportunidade, e descontinuidade no processo de pesquisa. Outro fator relevante é o impacto causado pela extensão dos períodos de patente. Essa extensão diminui o número de firmas sobreviventes no mercado e aumenta a parcela de mercado das firmas inovadoras e a média de concentração em cada categoria terapêutica; resumindo, um regime de proteção às patentes forte, implica em menor diversificação para cada firma e em maior concentração de mercado em vários segmentos da indústria farmacêutica (Malerba e Orsenigo, 2002).

Além disso, o processo de desenvolvimento de um medicamento, desde a pesquisa inicial, passando pelos testes clínicos, até a etapa final de publicidade e comercialização, é extremamente complexo, e pode levar até quinze anos. O processo, envolvendo descoberta de novos farmoquímicos e testes clínicos, ocorre, no entanto, somente no caso de medicamentos inovadores. No caso dos genéricos, o processo de desenvolvimento é diferente, pois eles 
são cópias de medicamentos anteriormente desenvolvidos, os quais tiveram suas patentes expiradas. Logo, o processo é um pouco diferenciado e os testes aos quais estes são submetidos são os de bioequivalência (Capanema e Palmeira Filho, 2007).

Recentemente, sobretudo a partir da década de 1990, a indústria farmacêutica vem passando por mudanças, como os movimentos de fusão e aquisição, buscando escala, novas capacitações e diminuir a concorrência e a verticalização, a fim de focar nas principais capacitações das empresas, com subcontratação de outras atividades para a realização das etapas da produção não contempladas internamente. Além disso, o advento dos genéricos, originados formalmente em 1984, com a Lei Hatch-Waxman, nos EUA, e a expiração da patente de diversos medicamentos, têm contribuído para a ascensão de novos países a esse mercado, inclusive Brasil e Índia.

\section{O desenvolvimento da indústria farmacêutica brasileira e indiana}

O mercado farmacêutico brasileiro apresenta uma trajetória crescente, como pode ser visto no gráfico 1 abaixo, figurando, hoje, como o oitavo mercado farmacêutico, no mundo. A indústria farmacêutica caracteriza-se, no Brasil, pela presença expressiva de empresas nacionais, voltadas ao segmento de genéricos e ao mercado interno, com cinco das dez maiores empresas do mercado apresentando tais características. Entretanto, a balança comercial brasileira de produtos farmacêuticos apresenta déficit crescente, principalmente no que diz respeito a produtos com maior conteúdo tecnológico, como os farmoquímicos (Interfarma).

O setor farmacêutico teve início na década de 1920, quando os primeiros laboratórios nacionais começaram a ser instalados. Nesse período, já existiam alguns importantes laboratórios de pesquisa, criados no século XIX, em sua maioria, que contribuíam com as empresas nacionais recentemente instaladas, efetuando pesquisa básica e na área de biologia (Urias, 2009).

Nas décadas de 1940 e 1950, a estratégia expansionista dos grandes grupos farmacêuticos mundiais, associada ao incentivo governamental à entrada de capital estrangeiro, fez com que muitas destas empresas entrassem no país. Contudo, elas não tinham como objetivo desenvolver atividades com maior conteúdo tecnológico no país; a atuação delas estava centrada na importação de tecnologias e mão-de-obra estrangeira, executando aqui apenas as etapas mais simples do processo produtivo (Urias, 2009). Assim, a participação dessas empresas na produção farmacêutica brasileira subiu de 14\% do total, em 1930, e 35\%, em 1940, para 73\%, em 1960 (Filho e Pan, 2003).

A partir da década de 1960, algumas iniciativas foram tomadas, visando a diminuição da dependência da indústria local em relação aos produtores 
estrangeiros, principalmente no que diz respeito à matéria-prima. Porém, muitas dessas iniciativas ficaram apenas no papel, sendo uma delas a Farmobrás (Farmoquímica Brasileira). A ideia começou a ser discutida ainda na década de 1960 e teria como objetivo o estabelecimento de um centro de pesquisas, no país, facilitando a produção local de matérias-primas, mas ela não chegou a ser efetivamente implantada (Bermudez, 1994).

GRÁFICO 1- FATURAMENTO DA INDÚSTRIA FARMACÊUTICA BRASILEIRA (US\$ MILHÕES)

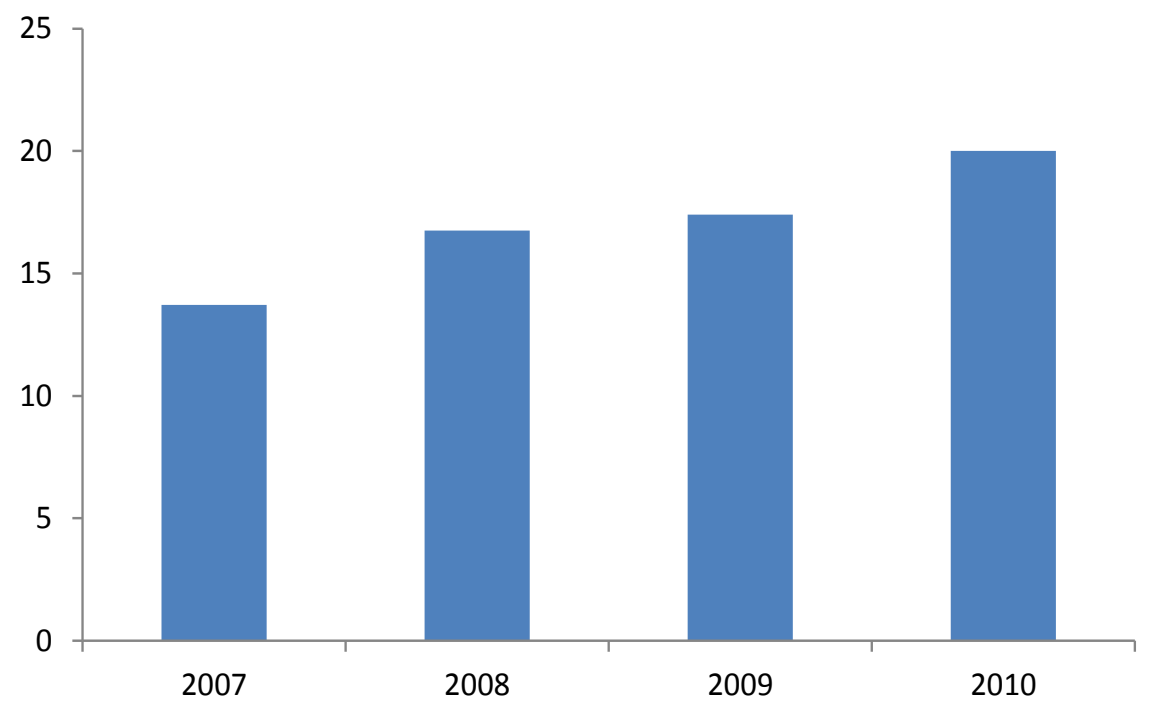

Fonte: Elaboração prórpia, a partir de dados de IMS Health, 2011.

Algumas políticas implementadas podem ser caracterizadas em duas vertentes. Uma mais vinculada à política industrial, e outra às ações da saúde. Relacionada à primeira vertente, temos a criação do Conselho de Desenvolvimento Industrial (CDI), a partir de 1965, e extinto em 1990. Esse Conselho, também atuante no setor farmacêutico, teve como antecedentes a Comissão Parlamentar de Inquérito da Indústria Farmacêutica, iniciada em 1961, e a constituição do Grupo Executivo da Indústria Farmacêutica (Geifar), sendo que, após sua Constituição, as atividades anteriormente desempenhadas pelos órgãos citados, passaram a ser realizadas por ele. Na outra vertente, temos a criação da Central de Medicamentos (Ceme), em 1971, que acabou respondendo apenas pela compra de medicamentos (Bermudez, 1994).

Em 1969, foi suspenso o reconhecimento de patentes para os processos de obtenção de fármacos e medicamentos, com o objetivo de melhorar as condições de produção e aprendizado, além de melhorar o ambiente competitivo. Contudo, essa condição não é suficiente para garantir o aprendizado e desenvolvimento de um setor de alta tecnologia e baseado em ciência, como 
é o farmacêutico. O não reconhecimento das patentes de medicamentos no Brasil, em vigor a partir de 1971, fez com que as empresas brasileiras lançassem cópias de produtos patenteados no país, com a sua marca, dando origem aos medicamentos similares. Entretanto, os fármacos utilizados na produção desses medicamentos eram importados de países europeus, como Itália e Espanha (Filho e Pan, 2003), ou seja, mesmo com a produção de cópias, não houve o desenvolvimento de capacitações internas, pois as etapas realizadas pelas empresas brasileiras continuaram sendo aquelas com menor conteúdo tecnológico.

O papel do Estado na industrialização brasileira foi de grande importância para o desenvolvimento de vários segmentos. Entretanto, quando nos referimos à indústria farmacêutica, o papel do Estado não é tão notável. Mesmo com políticas de incentivo ao setor, não houve a intenção de desenvolver fármacos inovadores. O esforço tecnológico esteve mais concentrado na engenharia reversa do que na inovação. Essa direção do esforço tecnológico condiz com o modelo de substituição de importações para abastecer o mercado interno, que contribuiu para o desenvolvimento de vários segmentos industriais (Avila, 2004).

Na década de 1980, devido às dificuldades da economia nacional, foram impostas restrições às importações. Com isso, a indústria nacional se viu obrigada a aumentar a produção de matérias-primas, o que levou a uma maior verticalização do setor (Urias, 2009).

Em 1984, com a Política Interministerial, houve um aumento do incentivo a produção de fármacos no Brasil, através da elevação das tarifas de importação de alguns insumos. Contudo, o objetivo da política de fazer com que novas plantas fossem instaladas no país, a fim de suprir a necessidade de insumos foi frustrado, com a abertura econômica na década de 1990 (Filho e Pan, 2003).

No Brasil, o ambiente regulatório passou por mudanças a partir da década de 1990, como a Lei de Patentes, obedecendo ao que foi estabelecido pelo Acordo TRIPS, que passou a vigorar em maio de 1997. Em janeiro de 1999, foi criada a Agência Nacional de Vigilância Sanitária (Anvisa). A agência tinha atribuições relacionadas ao suporte técnico na concessão de patentes pelo Instituto Nacional de Propriedade Industrial (INPI), controlando ainda a publicidade de produtos sujeitos ao regime de vigilância sanitária. A constituição da Anvisa criou as bases para uma elevação dos padrões sanitários da produção nacional e as pré-condições para eventuais incrementos das exportações (Filho e Pan, 2003).

Ainda em 1999, foi implantada a Lei dos Genéricos, muito importante para as empresas brasileiras, pois, como os gastos na produção e as barreiras a entrada neste segmento são menores, muitas empresas nacionais, incluindo as estudadas na sequência, cresceram especializando-se nesse segmento. 
No período de 1998 a 2002, o movimento estratégico predominante nas subsidiárias brasileiras das empresas multinacionais foi o de desativar suas produções locais de farmoquímicos, passando a importá-los das matrizes. Algumas empresas passaram mesmo a importar os medicamentos prontos, realizando no país somente a atividade comercial, correspondente ao quarto estágio. Os produtores nacionais de farmoquímicos foram afetados de forma particularmente severa. De acordo com a Associação Brasileira das Indústrias de Química Fina, Biotecnologia e suas Especialidades (Abifina), mais de mil plantas produtoras de produtos da química fina foram desativadas na década de 1990 (Filho e Pan, 2003).

A partir da década de 2000, o BNDES (Banco Nacional de Desenvolvimento Econômico e Social), passou a atuar de forma mais ativa quanto ao incentivo de alguns setores, principalmente a partir de 2004 com o lançamento da PITCE (Política Industrial, Tecnológica e de Comércio Exterior) pelo MDIC. A PITCE concentrava-se em setores dinâmicos, intensivos em conhecimento e inovação, como semicondutores, software, bens de capital e farmacêutica, o que inclui a oferta de crédito diferenciada. Assim, ainda em 2004 foi lançada a Profarma (Programa de Apoio ao Desenvolvimento da Cadeia Produtiva Farmacêutica), que contribuiria para a implementação da PITCE. Para uma melhor atuação, o Profarma foi dividido em três subprogramas: Profarma-Produção; Profarma-Fortalecimento de Empresas de Controle Nacional; e Profarma-P, D\&I (Bastos, 2005).

Outra ação governamental em relação à indústria farmacêutica foi a Política Nacional de Plantas Medicinais e Fitoterápicos, de 2006. De acordo com a Febrafarma, um terço da população brasileira não tem possibilidade alguma de ter acesso a medicamentos. A Anvisa instituiu uma regulamentação diferenciada para fitoterápicos. Essa diferenciação é importante, pois possibilita a geração de valor no mercado de fitoterápicos de eficácia comprovada (Capanema e Palmeira Filho, 2007).

Atualmente, o complexo farmacêutico brasileiro é composto sobretudo por divisões de empresas multinacionais, focadas nas etapas de menor valor agregado; por empresas nacionais, com pouca capacidade de inovação e voltadas ao mercado interno; e por um pequeno grupo de empresas de biotecnologia (Avila, 2004; Santos, 2010). Contudo, as empresas nacionais têm apresentado significativo crescimento, aumentando os investimentos em P\&D, inclusive na área de biotecnologia, apesar de os esforços registrados estarem ainda muito aquém dos que são realizados em outros países, como a Índia.

De acordo com a Pesquisa de Inovação Tecnológica (PINTEC), realmente, está havendo certa melhora na indústria farmacêutica local, embora ainda insuficiente, quando avaliamos o número de empresas pesquisadas e o número de empresas que mantém atividades de $\mathrm{P} \& \mathrm{D}$ in house.

Considerando que a indústria farmacêutica é intensiva em ciência, com alto 
gasto em $\mathrm{P} \& \mathrm{D}$, a proporção de empresas que desenvolvem atividade de $\mathrm{P} \& \mathrm{D}$ fica em torno de $50 \%$. Nesse âmbito, notamos que há uma diminuição na porcentagem de empresas que praticam tal atividade, pois o aumento do número de empresas não corresponde a uma ampliação na mesma taxa do número de empresas que fazem $\mathrm{P} \& \mathrm{D}$. Assim, há um aumento no número de empresas, mas este aumento não está focado, na maioria das vezes, em atividades de alto conteúdo tecnológico, que exijam atividades mais intensas de P\&D.

TABELA 1 - INDICADORES DA PINTEC

\begin{tabular}{c|c|c|c}
\hline Ano & $\begin{array}{c}\text { Número } \\
\text { de empre- } \\
\text { sas }\end{array}$ & $\begin{array}{c}\text { Inovação de } \\
\text { produto e/ou } \\
\text { processo }\end{array}$ & $\begin{array}{c}\text { Número de } \\
\text { empresas com } \\
\text { atividade interna } \\
\text { de P\&D }\end{array}$ \\
\hline 2003 & 245 & 250 & 131 \\
2005 & 255 & 313 & 117 \\
2008 & 301 & 315 & 144 \\
\hline
\end{tabular}

Fonte: elaboração própria a partir da PINTEC 2003, 2005 e 2008.

O mercado farmacêutico indiano aparece como o décimo segundo mercado mundial, com trajetória crescente de faturamento, como pode ser visto no gráfico 2 abaixo:

\section{GRÁFICO 2- FATURAMENTO DA INDÚSTRIA FARMACÊUTICA INDIA- NA (US\$ MILHÕES)}

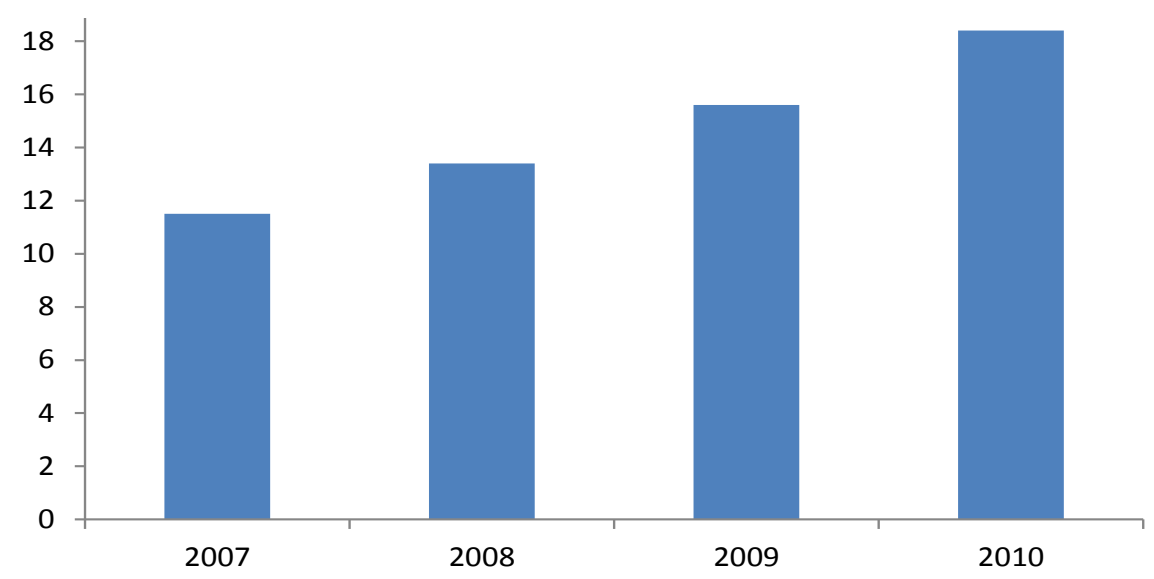

Fonte: elaboração própria, a partir de dados da India Brand Equity Foundation, 2011.

O país possui um conjunto de empresas especializadas em genéricos, que 
investem cada vez mais em P\&D e na produção de farmoquímicos, atuando tanto no mercado interno, como externo. Além disso, principalmente durante a década de 1990, e mais intensamente nos anos 2000, o país tem sido destino de investimentos de grandes multinacionais farmacêuticas, que buscam aproveitar as capacitações locais e a mão-de-obra barata e altamente capacitada. O país também é um dos destinos preferidos de outsourcing, tanto de P\&D, como de manufatura e testes clínicos. Além dos baixos custos, o país possui uma estrutura consolidada na pesquisa farmacêutica e médica, centralizada na cidade de Hyderabad, contando com 40 laboratórios, universidades e institutos de pesquisa.

A indústria farmacêutica no país teve origem durante a era colonial, durante a II Guerra Mundial a Índia começou a produzir timidamente alguns medicamentos, como vacinas e drogas para disenteria e lepra. Com a independência, em 1947, a Índia adotou uma política que visava a auto-suficiência, portanto, o governo investiu na indústria e restringiu as importações (Chaudhuri, 1997), contudo, até as décadas de 1950 e 1960, ela foi dominada por firmas estrangeiras e os preços dos medicamentos estavam entre os mais altos do mundo (Ray, 2008). O governo indiano criou alguns institutos de pesquisa na forma de Institutos Centrais de Pesquisa em Medicamentos, e investiu no setor de empresas públicas, a fim de estabelecer uma indústria farmacêutica nacional, visando, principalmente, diminuir as importações de medicamentos. Os institutos de pesquisa, juntamente com as empresas públicas e as subsidiárias de multinacionais que se instalaram no país posteriormente, possibilitaram a criação de uma base de conhecimento para a indústria.

No período de 1955 a 1965, segundo e terceiro planos qüinqüenais, o setor apresentou crescimento significativo. Nesse período foram firmadas parcerias com firmas de países europeus para a produção de drogas sintéticas, além disso, o país recebeu financiamento e apoio técnico de órgão vinculados a ONU (Chaudhuri, 1997).

Durante a década de 1970, a estrutura política adotada teve ênfase na substituição de importações. Com a introdução da Lei de Patentes de 1970, houve um esforço na geração de capacidade tecnológica local, no setor, com o objetivo de aumentar o acesso aos medicamentos. Durante esse período, o país passou por várias políticas governamentais, que configuraram um ambiente favorável ao crescimento desse setor. Entre essas políticas destacam-se as Ordens de Controle de Preço de Medicamentos (DPCO), de 1970, a Lei de Regulação de Câmbio Estrangeiro (FERA), de 1973, a Nova Política de Medicamentos, de 1978, e a Lei de Patentes de 1970 (Ray, 2008).

Em 1979, a DPCO expandiu o controle de preços para cerca de 80\% da indústria farmacêutica indiana, em termos de valor, sob regulação de preços (RAY, 2008). A FERA tinha como objetivo restringir e regular as operações das empresas estrangeiras na Índia, a fim de proteger e desenvolver capacidades industriais e tecnológicas nacionais. No setor farmacêutico foi permitido que 
até $51 \%$ do capital fosse estrangeiro. Essa política foi reforçada em 1978, com a Política de Medicamentos, que tinha três objetivos: autoconfiança na tecnologia farmacêutica nacional, auto-suficiência na produção de medicamentos e disponibilidade fácil e barata de medicamentos (Ray, 2008). Além disso, a FERA impedia que as empresas enquadradas por ela, produzissem alguns medicamentos (Lalitha, 2002). A Lei de Patentes de 1970 contribuiu para a redução das barreiras à entrada no setor, legalizando a engenharia reversa e construindo o caminho para que as firmas criassem capacitações básicas na P\&D farmacêutica (Kale e Little, 2007). Ela eliminou a proteção patentária a produtos, reduziu o período de proteção patentária de processos de vinte para sete anos e permitiu o licenciamento automático dos medicamentos (Kettler e Modi, 2000). Além disso, apenas as substâncias fabricadas na Índia tinham direito à proteção de patentes (Ray, 2008).

Na década de 1970, o setor indiano era dominado por filiais de grandes multinacionais farmacêuticas, sendo que das dez maiores empresas, em termos de venda, instaladas no país, apenas duas eram indianas (Kettler e Modi, 2000). As políticas implantadas nesse período visavam não apenas o aumento da produção e a acessibilidade, mas também, e principalmente, a criação de conhecimento e competências nesse setor, buscando diminuir a dependência da indústria local em relação a tecnologias importadas.

Com os institutos de pesquisa que haviam sido criados em 1950 e 1960, o país contava com capacitações que permitiam a adaptação de tecnologias desenvolvidas em outros países à realidade das empresas indianas, fundamental para o desenvolvimento industrial vivido nessa época (Lalitha, 2000). Muitas empresas começaram com atividades tecnológicas mais simples, para adquirir capacidades mais complexas, em um estágio posterior. Essa acumulação de capacidade tecnológica, possibilitada pela engenharia reversa, de revolução de processo na indústria farmacêutica indiana. Com isso, o crescimento da indústria de medicamentos foi de 21 e $11 \%$ ao ano durante as décadas de 1970 e 1980, respectivamente (Ray, 2008).

Na década de 1980, grande parte das firmas indianas tinha grande produção de medicamentos e fazia as formulações utilizadas no mercado local, com o que as empresas líderes locais começaram a explorar mercados na Ásia e na África (Athreye et al., 2009). No fim dos anos 1980, as firmas indianas estavam produzindo praticamente todas as novas moléculas, sem conhecer os detalhes do processo de P\&D da companhia inovadora. Como consequência do intenso uso da engenharia reversa, a indústria indiana construiu fortes capacitações em química orgânica e inorgânica, mas em outras áreas da P\&D inovadora, como química medicinal e biologia continuou fraca (Kale e Little, 2007). Os lucros e retornos das empresas indianas eram baixos, consequentemente, o investimento em P\&D também era baixo e concentrava-se no desenvolvimento de processos para drogas já conhecidas (Kettler e Modi, 2000). Durante a década de 1980 e a anterior, com a política protecionista do governo e o regime 
de propriedade intelectual permissivo, muitas multinacionais deixaram o país, pois os produtos lançados no mercado indiano, rapidamente eram copiados por empresas locais. Contudo, essas empresas voltaram a investir no país, nas décadas de 1990 e 2000.

Inicialmente, as empresas indianas exportavam formulações para os países menos desenvolvidos e em desenvolvimento. Entretanto, após 1990 o país começou a exportar formulações para o mercado de genéricos de países em desenvolvimento. A expansão em direção ao mercado americano de ocorreu com a Lei Waxman-Hatch, de 1984, que aboliu os testes clínicos em medicamentos genéricos e os substituiu pelos testes, mais simples, de bioequivalência, o que fez com que os custos e o valor de produção desses medicamentos caíssem. A partir de 1995, grandes firmas indianas começaram a investir pesadamente na pesquisa para descoberta de novas drogas. Muitas firmas começaram a investir parte da renda gerada pelos genéricos em pesquisas para medicamentos inovadores (Kale e Modi, 2000), o que não foi realizado tão amplamente pelas empresas brasileiras.

O processo de reforma da Índia começou com as reformas comerciais que procuravam reduzir, racionalizar e, eventualmente, eliminar todas as formas de restrições comerciais, tarifas, licenças de importação e exportação, restrições quantitativas e outras barreiras não-tarifárias. Além disso, também foram implantadas políticas para o investimento menos rígidas do que as anteriores. A FERA, de 1973, foi modificada para a Lei de Administração de Câmbio Estrangeiro (FEMA), em 1999. A FEMA permitiu que as multinacionais farmacêuticas aumentassem sua participação no capital de empresas da Índia para até 74\% (Ray, 2008).

A Lei de Patentes implantada em 2005 foi um reflexo direto dos acordos da OMC. A Índia optou por utilizar o prazo máximo estabelecido pelo Acordo TRIPS, para a adequação do regime de propriedade intelectual, contrariamente ao Brasil, que lhe concedia até janeiro de 2005. Com o novo regime, a prática da engenharia reversa foi abandonada e a pesquisa básica e de fronteira foram mais incentivadas. A indústria também passou por reformas, com um desinvestimento nas unidades do setor público e a redução dos benefícios ao setor de pequena escala (Ray, 2008).

Atualmente, a P\&D das empresas indianas - em oposição às necessidades do país, fortemente atingido por doenças tidas como negligenciadas, típicas de países pobres - concentra-se nas mesmas áreas das grandes empresas estrangeiras. A maior das razões para isso é a relevância dos mercados consumidores, já que as empresas locais têm pretensão de assumir importância em nível global e o maior importador dos medicamentos indianos são os EUA. Ademais, medicamentos para doenças como diabetes e câncer obtêm aprovação mais rápida pela agência reguladora americana, a FDA, e têm mais possibilidades de lucro do que em outras áreas (Kettler e Modi, 2000). 
A prática da $\mathrm{P} \& \mathrm{D}$ nas empresas farmacêuticas locais é um destaque do país. Como o número de empresas do setor é muito alto, existindo diversas pequenas empresas, a média de investimento ainda é considerada baixa, mas, observando-se as grandes empresas indianas, são verificados valores que chegam a $14,7 \%$ das vendas.

Para a indústria indiana, ainda há necessidade de catching up em termos de qualidade. Contudo, o país apresenta resultados muito promissores, com um market share, em nível global, de 22\%, no segmento de genéricos, e com o maior número de unidades produtivas autorizadas pelo FDA, 119 no total (KPMG, 2006).

Ao analisar a evolução dos setores, no Brasil e na Índia, podemos ver que, no caso da Índia, há implantação de um conjunto de políticas relativamente articuladas, que atuam em várias frentes, como no controle dos investimentos estrangeiros e na criação de uma estrutura de C\&T, através dos institutos de pesquisa e da mão-de-obra barata e qualificada, criando um ambiente que favoreceu o acúmulo de capacitações e possibilitou às empresas nacionais, que em um primeiro momento estavam baseadas essencialmente em genéricos, dessem um passo à frente, em direção à $\mathrm{P} \& \mathrm{D}$ de medicamentos inovadores e de insumos de alto conteúdo tecnológico. Enquanto isso, ao analisarmos o Brasil, vemos uma indústria que apresenta evolução, mas em um ritmo muito mais lento. Além disso, a trajetória do setor, no país, mostra um conjunto de políticas desarticuladas, que não priorizam o acúmulo de capacitação tecnológica, mas sim, e principalmente, de capacidade produtiva, mostrando-se incapaz de dar suporte dinâmico, isto é, quando considerada as necessidades em evolução, no tempo, a um setor da complexidade do farmacêutico.

\section{Análise das empresas selecionadas}

A fim de analisar o desenvolvimento recente das indústrias farmacêuticas nacionais e o efeito das políticas implantadas tanto pelo Brasil como pela Índia sobre elas, algumas empresas foram pesquisadas com maior nível de detalhamento, as quais foram selecionadas de acordo com seu faturamento.

Para analisar a capacitação dessas empresas, foram utilizados dados referentes às áreas de atuação (empresas que atuam na pesquisa de novos medicamentos ou na fabricação de farmoquímicos têm maior capacitação do que aquelas que atuam apenas na formulação ou na fabricação de genéricos); gastos em P\&D em relação ao faturamento, no ano de 2009; número de patentes no período 1990-2010 (principal forma de apropriação do conhecimento nesse setor), de acordo com a base ISI Web of Knowledge, como proxy de capacitação tecnológica; publicações no período 1990-2010, de acordo com a base Scopus (proxy da pesquisa básica, captando também a interação das empresas com outras instituições); e, por fim, como proxy de competitividade, os países para os quais seus produtos são exportados. 
A adoção do número de publicações como indicador de P\&D foi inspirada pelos estudos realizados no fim da década de 1990, que constataram haver um aumento do número de publicações feitas por pesquisadores vinculados a empresas farmacêuticas, em associação com outros pesquisadores, que atuavam em universidades. Esse aumento poderia ser explicado pela preocupação das empresas em melhorar suas capacitações em ciência básica e pela tendência de crescimento no papel das universidades como centros de produção de conhecimento e a interação entre essas instituições e empresas (Mowery e Sampat, 2004).

Os autores que escreveram sobre a importância da realização de pesquisa básica por empresas afirmam que esse tipo de pesquisa é importante para o desenvolvimento de futuras inovações e que a pesquisa básica funciona como um "bilhete de entrada" no mundo da ciência e do conhecimento (Freeman 1974), além de gerar vantagens para a firma.

De acordo com um estudo realizado, em 2009, pela Fiocruz, as empresas farmacêuticas brasileiras líderes em venda, em 2008, foram a Aché, EMS Sigma Pharma e Eurofarma. A German Chemicals Association efetuou um estudo semelhante em 2005, na Índia, mostrando que as maiores empresas daquele país em termos de venda eram Ranbaxy, Cipla e Dr. Reddy's.”, para "De acordo com a base de dados maiores e melhores, da revista Exame, as empresas farmacêuticas brasileiras líderes em venda, em 2008, foram a Aché, EMS Sigma Pharma e Eurofarma. A German Chemicals Association efetuou um estudo semelhante em 2005, na Índia, mostrando que as maiores empresas daquele país em termos de venda eram Ranbaxy, Cipla e Dr. Reddy's.

Os dados obtidos sobre as empresas selecionadas estão sintetizados nas duas tabelas abaixo.

As tabelas evidenciam as diferenças existentes entre os setores farmacêuticos brasileiro e indiano. As empresas indianas, apesar de não tão maiores do que as brasileiras atuam em segmentos que exigem maior conteúdo tecnológico, como o de farmoquímicos e novos medicamentos, além de atuarem em toda a cadeia produtiva, desde a P\&D inicial até a comercialização final, enquanto as empresas brasileiras ainda se restringem à fabricação de genéricos e estão focadas nas duas últimas etapas da cadeia, formulação final e comercialização.

Além disso, as empresas indianas apresentam maior importância dentro do mercado mundial, estando presentes em diversos países, principalmente na Europa, Estados Unidos e Japão, onde o controle de qualidade e as normas sanitárias são mais rígidas. Isto evidencia o fato de que as indianas são mais competitivas e têm uma estratégia mais focada no mercado estrangeiro, ao contrário das brasileiras, sendo que mais da metade da produção delas é exportada. Já as empresas brasileiras, apresentam uma tímida estratégia de expansão, estando ainda muito centradas no mercado interno. A entrada nesses mercados é importante, pois ela também está associada à P\&D. De 
Acordo com Urias (2009:45):

"É necessário investir em pesquisa capaz de resultar em medicamentos que, utilizando diferentes rotas de síntese e diferentes formulações, por exemplo, obtenham resultados clínicos bioequivalentes, sem serem simples cópias dos medicamentos de referência."

TABELA 2 - DADOS DAS EMPRESAS SELECIONADAS

\begin{tabular}{|c|c|c|c|c|}
\hline Empresa & País & $\begin{array}{l}\text { Vendas } \\
\text { (US\$ mi) }\end{array}$ & Atuação & $\begin{array}{c}\text { Destinos de Expor- } \\
\text { tação }\end{array}$ \\
\hline EMS & Brasil & 957 & $\begin{array}{l}\text { Medicamentos } \\
\text { similares e gené- } \\
\text { ricos }\end{array}$ & $\begin{array}{l}30 \text { países na América } \\
\text { Latina, Portugal, África } \\
\text { e Ásia }\end{array}$ \\
\hline Aché & Brasil & 705 & $\begin{array}{l}\text { Medicamentos } \\
\text { similares, gené- } \\
\text { ricos }\end{array}$ & $\begin{array}{l}10 \text { países na Améri- } \\
\text { ca Latina, mais Cabo } \\
\text { Verde, Japão e Estados } \\
\text { Unidos }\end{array}$ \\
\hline Eurofarma & Brasil & 466 & $\begin{array}{l}\text { Genéricos e } \\
\text { medicamentos } \\
\text { de uso animal }\end{array}$ & América Latina \\
\hline Cipla & Índia & 1.094 & $\begin{array}{l}\text { Genéricos, } \\
\text { farmoquímicos } \\
\text { e novos medica- } \\
\text { mentos }\end{array}$ & $\begin{array}{l}125 \text { países na Europa, } \\
\text { América (incluindo Es- } \\
\text { tados Unidos) e Ásia }\end{array}$ \\
\hline $\begin{array}{l}\text { Dr. } \\
\text { Reddy's }\end{array}$ & Índia & 1.084 & $\begin{array}{l}\text { Serviços far- } \\
\text { macêuticos, } \\
\text { fabricação de } \\
\text { farmoquímicos e } \\
\text { genéricos }\end{array}$ & $\begin{array}{l}60 \text { países: Europa, Ásia, } \\
\text { Estados Unidos, Amé- } \\
\text { rica Latina e Austrália }\end{array}$ \\
\hline Ranbaxy & Índia & 957,6 & $\begin{array}{l}\text { Medicamentos } \\
\text { para uso ani- } \\
\text { mal, genéricos e } \\
\text { serviços farma- } \\
\text { cêuticos }\end{array}$ & 180 países \\
\hline
\end{tabular}

Fonte: Elaboração própria a partir dos sites e relatórios anuais das empresas.

*Vendas referentes ao ano de 2008.

Essa prática pode ser vista quando analisamos as empresas indianas, que, inicialmente, usavam da engenharia reversa para fazerem cópias de medicamentos. Entretanto, essa prática possibilitou que essas empresas criassem capacitações tecnológicas, que as permitiram produzir medicamentos genéricos de alto desempenho, tornando-se suficientemente competitivas para entrar em grandes mercados (Kale e Little, 2007; apud Urias, 2009). 
Ademais, além de estarem presentes com sua própria marca, as empresas indianas também são requeridas para outsourcing de $\mathrm{P} \& \mathrm{D}$, testes clínicos e manufatura. A preferência pelo país está baseada na alta capacidade produtiva e tecnológica que as empresas indianas apresentam no setor, e nos baixos custos, o que torna o processo de desenvolvimento e produção de medicamentos mais barato. O país é o destino preferido de outsourcing no setor farmacêutico, enquanto que essa prática no Brasil ainda é pouco comum, já que o país não apresenta a mesma capacitação tecnológica e nem as mesmas vantagens de custo de outros países, principalmente a Índia e, secundariamente, a China.

TABELA 3 - P\&D E RESULTADOS NAS EMPRESAS SELECIONADAS

\begin{tabular}{l|c|c|c}
\hline Empresa & $\begin{array}{c}\text { Gasto em P\&D em relação } \\
\text { ao faturamento (\%) }\end{array}$ & Patentes & Publicações \\
\hline EMS & 6 & 6 & 2 \\
Eurofarma & 7 & 2 & 2 \\
Aché & 10 & 31 & 4 \\
Cipla & 5 & 238 & 45 \\
Dr. Reddy's & 10,4 & 218 & 597 \\
Ranbaxy & 10,9 & 890 & 457 \\
\hline $\begin{array}{l}\text { Fonte: Elaboração própria a partir dos sites das empresas e das bases de dados ISI Web of } \\
\text { Knowledge e } S c o p u s .\end{array}$ \\
* Fastos em P\&D referentes ao ano de 2009. \\
*Patentes e publicações referentes ao período 1990-2010.
\end{tabular}

Através dos indicadores de $\mathrm{P} \& \mathrm{D}$, patentes e publicações, podemos medir as capacitações tecnológicas destas empresas. Mesmo havendo pouca diferença na porcentagem gasta em $\mathrm{P} \& \mathrm{D}$, em relação às vendas, os valores absolutos apontam para um montante superior despendido pelas indianas, embora, pensando no setor como um todo, os gastos das indianas ainda estejam aquém do que é despendido pelas maiores e mais inovadoras empresas do setor, no mundo, o que pode atrapalhar os planos de empresas, como Ranbaxy e Dr. Reddy's, de tornarem-se players globais também no segmento de novos medicamentos e não apenas no de genéricos.

Nos indicadores de publicações, que podemos usar como uma proxy da pesquisa básica e que capta a interação das empresas com outras instituições, é nítida a vantagem das empresas indianas, como também em patentes, que captam parte dos resultados da pesquisa aplicada e de seu resultado comercial potencial e mesmo efetivo, ou seja, da transformação, ao menos potencial, do 
conhecimento em retornos financeiros. Além de apresentarem números mais significativos em publicações e patentes, as empresas indianas interagem com mais universidades, dentro e fora do país, além de com institutos de pesquisa e hospitais especializados indianos.

Essa enorme diferença de capacitações existente entre as empresas dos dois países, mostrada por indicadores como número de patentes, publicações e áreas de atuação, pode ser justificada pela estrutura de C\&T existente nos dois países. Avaliando as políticas implantadas na Índia e no Brasil, mostradas nos capítulos anteriores, constatamos que as políticas implantadas pela Índia, além de apresentarem maior coesão, tiveram um foco voltado para o aumento da capacitação tecnológica interna, ou seja, a ação do governo indiano, tanto na implementação de políticas como na criação de empresas públicas e institutos de pesquisa voltados para o setor, contribuiu para a criação de um ambiente favorável ao investimento e desenvolvimento de pesquisas, possibilitando aprendizado e aumento de capacitações. Associado a isso, temos empresas com estratégia agressiva de expansão, as quais investiram fortemente na criação de capacitações que possibilitassem que elas se tornassem líderes, no segmento de genéricos, seja interna, seja externamente, investindo também, posteriormente, na pesquisa de novos medicamentos.

Já no Brasil, o que verificamos é um conjunto de iniciativas que tinham a intenção de incentivar o acúmulo de capacitações por empresas locais, mas que não surtiram o efeito esperado, muitas vezes por estas iniciativas não terem sido executadas da forma correta, ou por serem isoladas e não parte de um conjunto de políticas articuladas e coesas, que contribuíssem para a formação de uma real estrutura de C\&T, que apoiasse o desenvolvimento do setor como um todo. Associado a isso, temos empresas que só começaram a ganhar destaque no setor nacional recentemente, com a Lei de Genéricos de 1999, e que apenas criaram laboratórios de P\&D na última década, também pelo atraso na aprovação desta Lei.

\section{Considerações finais}

As indústrias farmacêuticas da Índia e do Brasil tiveram início em períodos próximos, mas apresentaram trajetórias diferentes. A partir da década de 1970, começa a haver uma diferenciação na trajetória do setor, em ambos os países. No Brasil, foram implantadas políticas que visavam o crescimento da produção e o desenvolvimento tecnológico. Contudo, as últimas não mostraram muito êxito, por diversos motivos, como problemas de financiamento, falta de infra-estrutura, entre outros. Já na Índia, as políticas implantadas, que também visavam o aumento da produção e o desenvolvimento tecnológico, com a segunda ganhando mais ênfase do que no Brasil, foram mais eficientes, pois encontraram maior respaldo no tocante à estrutura desenvolvida para atender a indústria, como universidades e institutos de pesquisa (Furtado et 
al., 2003).

Outra questão muito importante é a propriedade intelectual. No Brasil, de 1971 a 1997, foi adotada uma Lei de Patentes que impedia o reconhecimento de patentes para os processos de obtenção de fármacos e medicamentos. Contudo, como não houve políticas e incentivos que garantissem o aprendizado na produção e P\&D de fármacos, dava-se, na verdade, a importação de farmoquímicos para a execução das etapas de menor conteúdo no país, ou seja, o país fazia cópias de medicamentos patenteados, utilizando a matéria-prima de outros países. Logo, a intenção de favorecer o acúmulo de capacitações, através da liberdade no uso de um conhecimento antes protegido por patente, não obteve o resultado esperado (Furtado et al., 2003).

$\mathrm{Na}$ Índia, uma das medidas que visavam o desenvolvimento local foi uma Lei de Patentes extremamente fraca, que impedia a concessão de patentes a produtos e permitia a prática de engenharia reversa. Isso, aliado a incentivos a laboratórios, institutos de pesquisa, universidades e à formação de mão-de-obra qualificada, contribuiu para a geração de novas capacitações, na indústria local. Além disso, a Índia protegeu ao máximo a indústria nacional, sendo permissiva no controle de qualidade dos medicamentos (o que reduziu as barreiras à entrada, mas, posteriormente, atrapalhou as empresas que queriam exportar, pois seus produtos tinham má reputação), restringindo a possibilidade de investimento estrangeiro no setor.

Essas diferenças na abordagem política de ambos os países fez com que, hoje, os setores apresentassem significativas diferenças entre si. Enquanto a indústria indiana é altamente descentralizada e apresenta empresas locais com atuação significativa a nível mundial, o Brasil apresenta alta centralização, com o domínio de grandes multinacionais estrangeiras e apenas algumas empresas nacionais, sobretudo de maior porte, as quais têm sua atuação restringida, essencialmente, ao mercado doméstico.

A tendência mostrada pela análise das empresas mostra firmas indianas concentradas nas atividades de alta tecnologia do processo produtivo. Já entre as empresas brasileiras, a tendência observada é o investimento em biofármacos, área na qual a Índia é pioneira. As atividades e o investimento em P\&D ainda são baixos, sendo que algumas empresas nem sequer desenvolvem P\&D in house.

Exatamente neste sentido, outra diferença é a inserção internacional das empresas dentro do mercado mundial, com empresas brasileiras com atuação limitada, restrita às atividades de menor conteúdo tecnológico e ainda dependentes da importação de matéria-prima, e as empresas indianas com uma atuação mais abrangente, que se estende a todas as etapas da cadeia, inclusive com a prática de outsourcing de $\mathrm{P} \& \mathrm{D}$, manufatura e testes clínicos, o que se deve às capacitações internas e aos baixos custos destes outsourcings. Além disso, quando observamos números relativos a $\mathrm{P} \& \mathrm{D}$, como gastos, patentes e 
número de publicações, fica evidente a superioridade das empresas indianas em relação às brasileiras, com as primeiras investindo mais e gerando resultados quer em pesquisa básica, quer em pesquisa aplicada.

Essa distinção nos permite constatar que há diferenças quanto às capacitações tecnológicas da indústria, entre estes dois países, as quais podem ser melhor entendidas pela análise dos setores, desde seus primórdios. Como o acúmulo de capacitações é um processo path-dependent, as ações realizadas no passado, como as políticas empregadas e as ações das próprias empresas, têm grande influência sobre os resultados encontrados atualmente, o que justifica esta análise sob perspectiva histórica.

\section{Referências Bibliográficas}

Athreye, S; Kale, D; Ramani, S.V. (2009). "Experimentation with strategy and the evolution of dynamic capability in the indian pharmaceutical sector." Industrial And Corporate Change, 18(4) 729-759.

Avila, J. P. C. (2004). "O desenvolvimento do setor farmacêutico: a caminho de uma estratégia centrada na inovação.” Revista Brasileira De Inovação, 3 (2).

Bastos, V.D. (2005). "Inovação farmacêutica: padrão setorial e perspectivas para o caso brasileiro." Bndes Setorial, Rio De Janeiro, P. 271-295.

Bell, M.; Pavitt, K. (1993) "Industrial growth: contrasts between developed and developing countries." Industrial And Corporate Change, V.2, N.2.

Bermudez, J. (1994). "Medicamentos genéricos: uma alternativa para o mercado brasileiro.” Caderno De Saúde Pública, Rio De Janeiro, 3 (10): 368-378.

Capanema, L.X.L. \& Palmeira Filho, P.L (2007). "Indústria farmacêutica brasileira: reflexões sobre sua estrutura e potencial de investimentos.” Bndes Setorial, Rio De Janeiro, P.165-206.

Chaudhuri, S (1997). "The evolution of the indian pharmaceutical industry. In: Chaudhuri, S.; Felker, G.; György, K. (Orgs).” The pharmaceutical industry in india and hungary: policies, institutions and technological development.

David, P.A. (2000). "Path Dependence, Its Critics, And The Quest For 'Historical Economics'." Stanford University Working Paper N. oo-O11.

Freeman, C. (1974) “The economics of industrial innovation." Londres: Frances Pinter.

Filho, P.L.P. \& Pan, S.S.K (2003). "Cadeia farmacêutica no brasil: avaliação preliminar e perspectivas.” Bndes Setorial, Rio De Janeiro, (18):3-22.

Furtado, J.; Costa, I.; Zanatta, M.; Strachman, E. \& Queiroz, S.R. (2003). Fdi and technology policies in brazil. anais da conferência "The information society understanding its institutions interdisciplinary", European Association For Evolutionary Political Economy (Eaepe), Maastricht, Holanda, 7-10 Nov 2003.

Kale, D. \& Little, S. (2007). "From imitation to innovation: the evolution of r\&d capabilities and learning processes in the indian pharmaceutical industry." 
Technology Analysis \& Strategic Management, 18 (5):589-6o9.

Kattler, H.E. \& Modi, R. (2001) "Building local research and development capacity for the prevention and cure of neglected diseases: the case of india." Boletim Da Organização Mundial De Saúde, 79: 742-747.

Lalitha, N. (2002). "Indian pharmaceutical industry in wto regime: a swot analysis." Economic And Political Weekly, 37 (34): 3542-3555.

Malerba, F. \& Orsenigo, L. (2001). "Innovation and market structure in the dynamics of the pharmaceutical industry and biotechnology: towards a history friendly model." Druid Nelson And Winter Conference, Aalborg. Url [On Line]: http:// www.druid.dk/conferences/nw/paper1/malerba_orsenigo.pdf

Mowery, D.C. \& Sampat, B.N. (2004). "Universities in national innovation systems. artigo Apresentado No $1^{\circ}$ Globelics Academy." Portugal. Url [On Line]: http://smartech.gatech.edu/bitstream/handle/1853/43161/davidmowery_1. pdf? sequence $=1$

Nelson, R.R. \& Winter, S.G. (1982). "Introduction; further analysis of search and selection.” In: An Evolutionary Theory Of Economic.

Pintec (Pesquisa De Inovação). Url [On Line]: http://www.pintec.ibge.gov.br/

Prado, A. R. M. (2008). "Lei dos genéricos e concorrência na indústria farmacêutica brasileira." Tese De Mestrado, Universidade Estadual Paulista "Júlio De Mesquita Filho”, Programa De Pós-Graduação Em Economia.

Radaelli, V. (2006). “A inovação na indústria farmacêutica: forças centrípetas e forças centrífugas no processo de internacionalização.” Tese De Mestrado, Universidade Estadual De Campinas, Programa De Pós-Graduação Em Política Científica E Tecnológica.

Ray, A.S. (2008) “Aprendizagem e inovação na indústria farmacêutica indiana: o papel da ifi e outras intervenções políticas.” Reciis (Revista Eletrônica De Comunicação, Informação E Inovação Em Saúde), 2 (2):74-8o. Url [On Line]: http://www.reciis.cict.fiocruz.br/index.php/reciis/article/view/192/216

Santos, F. (2003). "The coevolution of firms and their knowledge environment: insights from the pharmaceutical industry." Technological Forecasting And Social Change, 70 (3):687-715.

Santos, M.C.B.G. (2010). "Estratégias tecnológicas em transformação: um estudo da indústria farmacêutica brasileira." Universidade Federal De São Carlos, Programa De Pós-Graduação Em Engenharia De Produção.

Strachman, E. (2009). "Políticas industriais: definição e importância (ou não) de fundamentação teórica (parte 2).” Economia \& Tecnologia 17 (5).

Teece, D.; Pisano, G. (1994). “The dynamic capabilities of firms: an introduction.” Industrial And Corporate Change, 3 (3).

Urias, E.M.P. (2009). "A indústria farmacêutica brasileira: um processo de co-evolução entre tecnologia, instituições e organizações industriais.” Tese De Mestrado, Universidade Estadual De Campinas, Programa De Pós-Graduação Em Política Científica E Tecnológica.

Kpmg (2006). “The indian pharmaceutical industry: collaboration for growth.” Disponível em: http://www.in.kpmg.com/pdf/indian\%2opharma\%2Ooutlook.pdf 
Sítios Consultados:

Aché (http://www.ache.com.br/home/)

Interfarma (http://www.interfarma.org.br/site2/)

Cipla (http://www.cipla.com/)

Dr. Reddy's (http://www.drreddys.com/)

Ems (http://www.ems.com.br/)

Eurofarma (http://www.eurofarma.bom.br/)

India Brand Equity Foundation (http://www.ibef.org)

Ranbaxy (http://www.ranbaxy.com/)

Exame (http://www.exame.abril.com.br)

Recebido em: 30 de outubro de 2012 Aceito em: 23 de março de 2013 
